\title{
Age Distribution of Aortic Sclerosis among Bangladeshi Population
}

\author{
Mohammed Abaye Deen Saleh ${ }^{1}$, Pratyay Hasan ${ }^{2}$, Khyrun Nahar $^{3}$, Abdul Wadud Chowdhury ${ }^{4}$, Mohsin Ahmed ${ }^{5}$, Syed \\ Rezwan Kabir6, Md. Gaffar Amin ${ }^{7}$, Kazi Nazrul Islam
}

\begin{abstract}
:
Aortic sclerosis (ASc) is defined as thickening or calcification of the aortic valve without significant obstruction of blood flow. Aortic sclerosis is diagnosed when in echocardiography, thickening and calcification of one or more cusps of a tricuspid aortic valve is manifested, whereas in aortic stenosis, cusp separation is restricted and the velocity through the aortic valve is $>2.5 \mathrm{~m} / \mathrm{s}$. Its prevalence increases with age. Aortic valve stenosis is associated with systemic endothelial dysfunction, and it carries a $50 \%$ increase in risk of cardiac death or myocardial infarction. As aortic sclerosis has proved to be more and more relevant in recent days, it has been important to identify epidemiological data and demographic information of aortic sclerosis in Bangladeshi population. This study tried to determine age distribution of aortic sclerosis in Bangladehsi population.
\end{abstract}

Median age of aortic sclerosis patients was 65 years (mean $67 \pm 12$ years), most of the patients (17.2\%) were in 56-60 years of age group. The same statement holds correct for females, where highest number of patients (7.7\% of total patients) were in the same age group. For the males, the highest number of patients $(11 \%$ of total patients) were in 61-65 years of age group. The minimum age was $\mathbf{4 5}$ years for both males and females. Although the minimum age is same for both sex, females are affected a bit earlier than males, and statistically significant difference was found between mean ages of two sexes. Most of the aortic sclerotic patients are below the usually used age cut off of 65 years. There is significant difference between mean age of presentation of aortic sclerosis between males and females. Further study should be undertaken to understand these effects more clearly.

Keywords: Aortic Valve, Cardiology, Sclerosis, Echocardiography, Age distribution.
1. Registrar, Department of Cardiology, Dhaka Medical College Hospital, Dhaka, Bangladesh.

2. Indoor Medical Officer, Department of Medicine, Dhaka Medical College Hospital, Dhaka, Bangladesh.

3. Outdoor Medical Officer, Pediatrics Outpatient Department, Dhaka Medical College Hospital, Dhaka, Bangladesh.

4. Professor \& Head, Department of Cardiology, Dhaka Medical College Hospital, Dhaka, Bangladesh.

5. Associate Professor, Department of Cardiology, Dhaka Medical College Hospital, Dhaka, Bangladesh.

6. Junior Consultant, Department of Cardiology, Dhaka Medical College Hospital, Dhaka, Bangladesh.

7. Assistant Professor, Department of Cardiology, Dhaka Medical College Hospital, Dhaka, Bangladesh.

8. Junior Consultant, Department of Cardiology, Dhaka Medical College Hospital, Dhaka, Bangladesh.

Address of Correspondence: Dr. Mohammed Abaye Deen Saleh, Registrar, Department of Cardiology, Dhaka Medical College Hospital, Dhaka, Bangladesh. Tel: +8801716066735, Email: sarahcosis@gmail.com.
(Bangladesh Heart Journal 2017; 32(1) : 50-54)

Introduction:

Aortic sclerosis (ASc) is defined as thickening or calcification of the aortic valve without significant obstruction of blood flow. ${ }^{1}$ Aortic sclerosis is diagnosed when in echocardiography, thickening and calcification of one or more cusps of a tricuspid aortic valve is manifested, whereas in aortic stenosis, cusp separation is reduced and the velocity through the aortic valve is > $2.5 \mathrm{~m} / \mathrm{s}^{2}$ Its prevalence increases with age..$^{1,3}$ In the Monica-KORA study of 935 European adults aged 35 to 84 years, the prevalence of aortic sclerosis increased across the age distribution from 7 percent in those age 35 to 44 years to 65 percent in those age 75 to 84 years. ${ }^{4}$ Aortic valve sclerosis is associated with systemic endothelial dysfunction, ${ }^{5}$ and it carries a $50 \%$ increase in risk of cardiac death or myocardial infarction. ${ }^{2}$ In 2279 middle aged African Americans, the presence of aortic sclerosis conferred a hazard ratio of 3.8 for myocardial

DOI: http://dx.doi.org/10.3329/bhj.v32i1.34171

Copyright $\odot 2017$ Bangladesh Cardiac Society. Published by Bangladesh Cardiac Society. This is an Open Access articles published under the Creative Commons Attribution-NonCommercial 4.0 International License (CC BY-NC). This license permits use, distribution and reproduction in any medium, provided the original work is properly cited and is not used for commercial purposes. 
infarction or fatal coronary heart disease after adjustment for multiple risk factors. ${ }^{6}$ It is also found that AV sclerosis is associated with several $\mathrm{CV}$ risk factors and predicted $\mathrm{CV}$ events independently of prevalent $\mathrm{CV}$ disease and traditional $\mathrm{CV}$ risk factors, including LV mass and ejection fraction. ${ }^{7}$ Sui et.al. found that there were significant similarities in clinical risk factors, histopathological alterations of AVS and coronary atherosclerosis. ${ }^{8} \mathrm{Kim}$ et.al. found that aortic valve sclerosis on echocardiography is a good predictor of coronary artery disease in patients with an inconclusive treadmill exercise test. ${ }^{9}$ As aortic sclerosis has proved to be more and more relevant in recent days, it has been important to identify epidemiological data and demographic information of aortic sclerosis in Bangladeshi population. This study tried to determine the age distribution of aortic sclerosis in Bangladeshi popualtion.

\section{Methods:}

\section{Sampling technique}

The patients were included from a diagnostic center, by consecutive sampling technique. All the patients that met the criteria of aortic sclerosis were included in this study. Enrollments of patients were done over one-year period.

\section{Two-dimensional transthoracic echocardiography}

2D transthoracic echocardiography was performed using a $4 \mathrm{MHz}$ Sequoia C256 probe (Medison Inc,). 2D echocardiographic tests and Doppler tests were performed following the Standard Practical Guideline for 2D echocardiography from the American Society of Echocardiography. ${ }^{10}$ The area of the aortic valve orifice on the sternal left margin was measured using a static image in which the 3 cusps were most widely open, while the aortic valve blood flow speed was measured in the apical 5-chamber view using a continuous wave Doppler. ${ }^{9}$ These measurements were taken three times and the average was used in analysis.

\section{Aortic valve sclerosis measurement}

Using a long axis view of the left sternal margin, valve thickness was defined as the value obtained by enlarging the area of the aortic valve, and measuring the thickest part of the right coronary aortic cusp as well as the noncoronary aortic cusp during the systolic period. Using a short axis view of the left sternum margin, when movements of the right coronary aortic cusp and noncoronary aortic cusp during the systolic period were examined by enlarging the aortic root, a valve opening inward concave was defined as normal, whereas a valve opening inward flat or inward convex was defined as showing restricted motion. ${ }^{11}$

\section{Definition of aortic sclerosis}

Patients were included as case of aortic sclerosis if they showed one the following criteria on trans-thoracic echocardiogram (TTE):9,12,13
1. Aortic cusp thickness was $>2 \mathrm{~mm}$

2. Aortic valve cusps showed restricted motion. AND,

3. Aortic jet velocity $(\mathrm{m} / \mathrm{s}) \leq 2.5 \mathrm{~m} / \mathrm{s}$. ${ }^{13,14}$

\section{Exclusion criteria}

1. Patients who did not meet either of the first two criteria.

2. Patients who did not give consent.

\section{Statistical analysis}

Statistical analyses were done with Statistical Package for Social Sciences (SPSS) version 23 (IBM Corporation, USA). Descriptive statistics and graphs are derived, and independent Student's $t$ test and Mann-Whitney $U$ test were employed to determine any significant differences between means.

Result:

A total of 209 patients were selected in this study, among which $135(64.59 \%)$ were male and $74(35.41 \%)$ were female (Figure 1).

Age distribution of the different sex groups are shown in Table 1 and 2 and Figure 2 and 3.

An independent sample $t$ test and Mann-Whitney $U$ test were employed assessing differences between mean age of male and female, both came significant $(p=0.014$, Table 3).

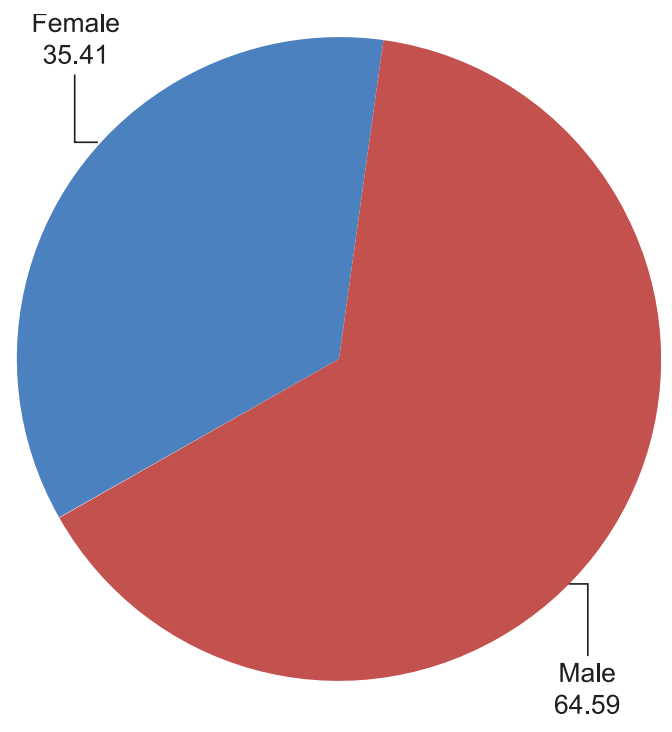

Fig.-1: Sex distribution 
Table-I

Age distribution of the patients in different sex groups

\begin{tabular}{|c|c|c|c|c|c|c|c|}
\hline & & & Mean & Median & Minimum & Maximum & Standard Deviation \\
\hline \multirow[t]{3}{*}{ Age } & Sex & Male & 68 & 70 & 45 & 100 & 12 \\
\hline & & Female & 64 & 65 & 45 & 90 & 11 \\
\hline & & Total & 67 & 65 & 45 & 100 & 12 \\
\hline
\end{tabular}

Table-II

Percentage of patients in different age groups

\begin{tabular}{|c|c|c|c|c|c|c|c|}
\hline & & \multicolumn{4}{|c|}{ Sex } & & \\
\hline & & \multicolumn{2}{|c|}{ Male } & \multicolumn{2}{|c|}{ Female } & \multicolumn{2}{|c|}{ Total } \\
\hline & & $\begin{array}{c}\text { Count } \\
\text { of total } \%\end{array}$ & Percentage & $\begin{array}{c}\text { Count } \\
\text { of total } \%\end{array}$ & Percentage & $\begin{array}{c}\text { Count } \\
\text { of total } \%\end{array}$ & Percentage \\
\hline \multirow[t]{13}{*}{ Age Categories } & $41-45$ & 3 & $1.4 \%$ & 1 & $0.5 \%$ & 4 & $1.9 \%$ \\
\hline & $46-50$ & 7 & $3.3 \%$ & 12 & $5.7 \%$ & 19 & $9.1 \%$ \\
\hline & $51-55$ & 12 & $5.7 \%$ & 7 & $3.3 \%$ & 19 & $9.1 \%$ \\
\hline & $56-60$ & 20 & $9.6 \%$ & 16 & $7.7 \%$ & 36 & $17.2 \%$ \\
\hline & $61-65$ & 23 & $11.0 \%$ & 7 & $3.3 \%$ & 30 & $14.4 \%$ \\
\hline & $66-70$ & 22 & $10.5 \%$ & 13 & $6.2 \%$ & 35 & $16.7 \%$ \\
\hline & $71-75$ & 13 & $6.2 \%$ & 9 & $4.3 \%$ & 22 & $10.5 \%$ \\
\hline & $76-80$ & 20 & $9.6 \%$ & 5 & $2.4 \%$ & 25 & $12.0 \%$ \\
\hline & $81-85$ & 8 & $3.8 \%$ & 1 & $0.5 \%$ & 9 & $4.3 \%$ \\
\hline & $86-90$ & 4 & $1.9 \%$ & 3 & $1.4 \%$ & 7 & $3.3 \%$ \\
\hline & $91-95$ & 0 & $0.0 \%$ & 0 & $0.0 \%$ & 0 & $0.0 \%$ \\
\hline & $96-100$ & 3 & $1.4 \%$ & 0 & $0.0 \%$ & 3 & $1.4 \%$ \\
\hline & Total & 135 & $64.6 \%$ & 74 & $35.4 \%$ & 209 & $100.0 \%$ \\
\hline
\end{tabular}

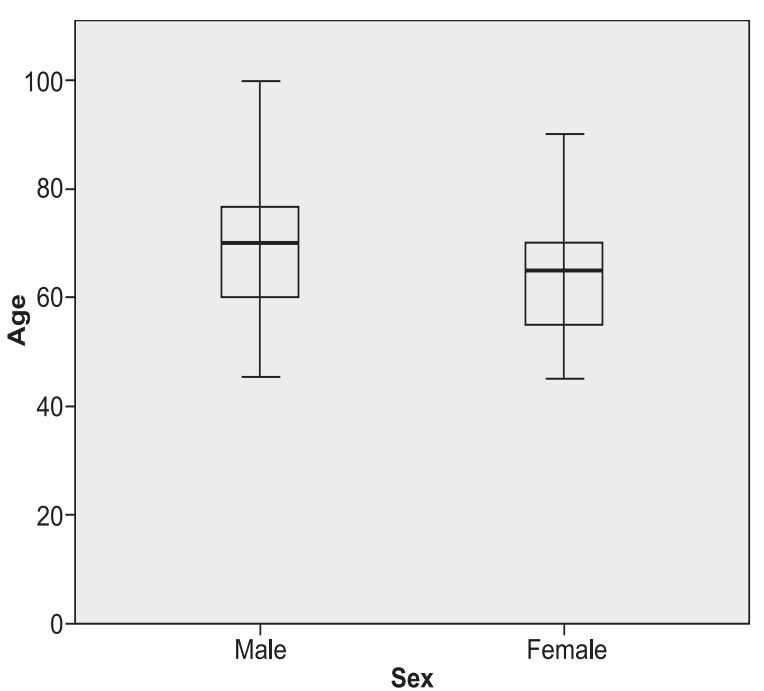

Fig.-2: Age distribution of the patients in different sex groups

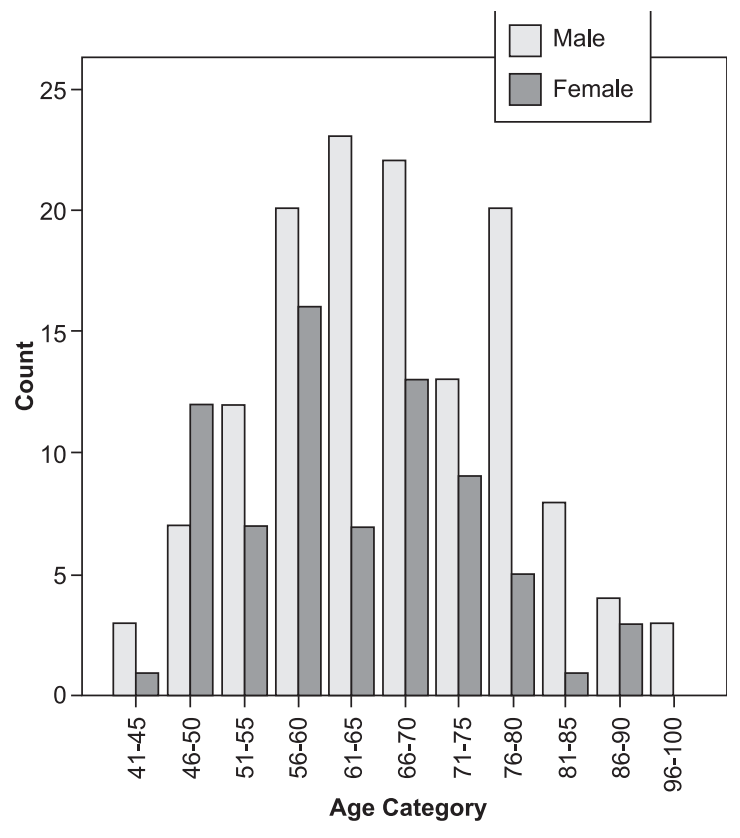

Fig.-3: Percentage of patients in different age groups 
Table-III

Independent sample $t$ test between two sex groups

\begin{tabular}{|c|c|c|c|c|c|c|c|c|c|c|}
\hline & & \multicolumn{2}{|c|}{$\begin{array}{l}\text { Levene's Test } \\
\text { for Equality } \\
\text { of Variances }\end{array}$} & \multicolumn{7}{|c|}{ t-test for Equality of Means } \\
\hline & & \multirow[t]{2}{*}{$\mathrm{F}$} & \multirow[t]{2}{*}{$P$ value } & \multirow[t]{2}{*}{$\mathrm{t}$} & \multirow[t]{2}{*}{$d f$} & \multirow[t]{2}{*}{$\begin{array}{l}\mathrm{P} \text { value } \\
\text { (2-tailed) }\end{array}$} & \multirow[t]{2}{*}{$\begin{array}{c}\text { Mean } \\
\text { Difference }\end{array}$} & \multirow[t]{2}{*}{$\begin{array}{l}\text { Std. Error } \\
\text { Difference }\end{array}$} & \multicolumn{2}{|c|}{$\begin{array}{c}95 \% \text { Confidence Interval } \\
\text { of the Difference }\end{array}$} \\
\hline & & & & & & & & & Lower & Upper \\
\hline \multirow[t]{2}{*}{ Age } & Equal variances assumed & .225 & .636 & 2.468 & 207 & .014 & 4.063 & 1.646 & .818 & 7.309 \\
\hline & Equal variances not assumed & & & 2.517 & 159.097 & .013 & 4.063 & 1.614 & .875 & 7.252 \\
\hline
\end{tabular}

\section{Discussion:}

From the results, it is evident, that although median age of aortic sclerosis patients was 65 years (mean $67 \pm 12$ years), most of the patients (17.2\%) were in 56-60 years of age group (Table 2, Figure 3). The same statement holds correct for females, where highest number of patients $(7.7 \%$ of total patients) were in the same age group. For the males, the highest number of patients (11\% of total patients) were in $61-65$ years of age group. The minimum age was 45 years for both males and females irrespectively. From the boxplot (Figure 2), we can see the picture more clearly. Although the minimum age is same for both sex, females are affected a bit earlier than males, and statistically significant difference was found between mean ages of two sexes (Table 3).

In a meta-analysis, collecting information from 22 studies, Coffey et.al. found an increase of $1.5 \%$ in prevalence per year of increase in average age of study participants (95\% confidence interval 0.75 to $2 \cdot 25 \%, p=0.0007, R^{2} 0.549$ ). This data is consistent with our findings, which shows most of the patients are from geriatric age groups. Völzke et.al. and Stewart et.al. reported age is an independent risk factor for aortic sclerosis. ${ }^{15,16}$

Stewart et.al. reported 5,201 subjects with $>65$ years of age enrolled in the Cardiovascular Health Study, aortic valve sclerosis was present in $26 \%$ and aortic valve stenosis in $2 \%$ of the entire study cohort; in subjects $>75$ years of age, sclerosis was present in $37 \%$ and stenosis in $2.6 \% .^{16}$ Stewart et. al. also reported in subjects $>75$ years of age, prevalence of sclerosis is $37 \% .^{16}$ But, in our study, $51.7 \%$ patients were below or up to 65 years of age, and $21 \%$ of patients were above 75 years of age. The reason for this may lie in the fact that many studies have been done where first a specific age group has been selected, and then the prevalence of aortic sclerosis or other CV outcomes statistics are determined in that age group. ${ }^{17}$ But we took a different approach and enrolled patients by consecutive sampling which allowed us to determine demographic information including age, etc. not restricted to some specific group. It is clearly seen in this study that most of the aortic sclerotic patients are actually below the usually used age cut off of 65 years.

In the Monica-KORA study of 935 European adults aged 35 to 84 years, the prevalence of aortic sclerosis increased across the age distribution from 7 percent in those age 35 to 44 years to 65 percent in those age 75 to 84 years. ${ }^{4}$ But in our study, we had only $1.9 \%$ patients in $41-45$ years age group, $16.3 \%$ in $76-85$ years age group.

It is well known that there are sex-related differences in atherosclerosis progression, plaque composition and prevalence of microvascular disease. ${ }^{18}$ But the differences of age of presentation of aortic sclerosis in different sexes are not well documented. In our study, there was significant difference between mean age of male and females. This finding contrasts with the results reported by Aksoy et.al. who did not find any such difference. ${ }^{19}$

\section{Conclusion:}

Most of the aortic sclerotic patients are actually below the usually used age cut off of 65 years. There is significant difference between mean age of presentation of aortic sclerosis between males and females. Further study should be undertaken to understand these effects more clearly.

\section{List of abbreviations}

ASc $=$ Aortic sclerosis

$\mathrm{CV}=$ Cardiovascular

LV = Left ventricle

TTE = Trans-thoracic echocardiogram

\section{Conflict of interest: None}

\section{References}

1. Coffey S, Cox B, Williams MJA. The prevalence, incidence, progression, and risks of aortic valve sclerosis: a systematic review and meta-analysis. J Am Coll Cardiol. 2014 Jul 1;63(25 Pt A):2852-61.

2. Nightingale AK, Horowitz JD. Aortic sclerosis: not an innocent murmur but a marker of increased cardiovascular risk. Heart. 2005;91(11):1389-93. 
3. Prasad Y, Bhalodkar NC. Aortic sclerosis-a marker of coronary atherosclerosis. Clin Cardiol. 2004 Dec;27(12):671-3.

4. Stritzke J, Linsel-Nitschke P, Markus MRP, Mayer B, Lieb W, Luchner A, et al. Association between degenerative aortic valve disease and long-term exposure to cardiovascular risk factors: results of the longitudinal population-based KORA/MONICA survey. Eur Heart J. 2009 Aug;30(16):2044-53.

5. Poggianti E, Venneri L, Chubuchny V, Jambrik Z, Baroncini LA, Picano E. Aortic valve sclerosis is associated with systemic endothelial dysfunction. J Am Coll Cardiol. 2003 Jan 1;41(1):136-41.

6. Taylor HA, Clark BL, Garrison RJ, Andrew ME, Han $\mathrm{H}$, Fox ER, et al. Relation of aortic valve sclerosis to risk of coronary heart disease in African-Americans. Am J Cardiol. 2005 Feb 1;95(3):401-4.

7. Olsen MH, Wachtell K, Bella JN, Gerdts E, Palmieri $\mathrm{V}$, Nieminen MS, et al. Aortic valve sclerosis relates to cardiovascular events in patients with hypertension (a LIFE substudy). Am J Cardiol. 2005 Jan 1;95(1):132-6.

8. Sui SJ, Ren MY, Xu FY, Zhang Y. A high association of aortic valve sclerosis detected by transthoracic echocardiography with coronary arteriosclerosis. Cardiology. 2007;108(4):322-30.

9. Kim D-B, Jung HO, Jeon DS, Park CS, Jang SW, Park $\mathrm{HJ}$, et al. Aortic Valve Sclerosis on Echocardiography is a Good Predictor of Coronary Artery Disease in Patients With an Inconclusive Treadmill Exercise Test. Korean Circ J. 2009 Jul;39(7):275-9.

10. Cheitlin MD, Armstrong WF, Aurigemma GP, Beller GA, Bierman FZ, Davis JL, et al. ACC/AHA/ASE 2003 guideline update for the clinical application of echocardiography: summary article: a report of the American College of Cardiology/American Heart Association Task Force on Practice Guidelines (ACC/AHA/ASE Committee to Update the 1997 Guidelines for the Clinical Application of Echocardiography). Circulation. 2003 Sep 2;108(9):1146-62.
11. Jeon DS, Lee MY, Kim CJ, Youn HJ, Cho EJ, Cho $\mathrm{JM}$, et al. The Severity of Aortic Valve Sclerosis is Associated with Carotid Intimia Media Thickness/ Plaque in Neurologically Asymptomatic Patient. Korean Circ J. 2004;34(11):1049-55.

12. Tolstrup K, Crawford MH, Roldan CA. Morphologic characteristics of aortic valve sclerosis by transesophageal echocardiography: importance for the prediction of coronary artery disease. Cardiology. 2002;98(3):154-8.

13. Baumgartner $\mathrm{H}$, Hung J, Bermejo J, Chambers JB, Evangelista A, Griffin BP, et al. Echocardiographic assessment of valve stenosis: EAE/ASE recommendations for clinical practice. J Am Soc Echocardiogr. 2009 Jan;22(1):1-23.

14. Classification of valve stenosis and regurgitation ECHOpedia [Internet]. [cited 2017 Apr 7]. Available from: http://www.echopedia.org/ wiki/Classification_ of_valve_stenosis_and_regurgitation\# bibkey_ ASEVS

15. Völzke H, Schwahn C, Hummel A, Wolff B, Kleine V, Robinson DM, et al. Tooth loss is independently associated with the risk of acquired aortic valve sclerosis. Am Heart J. 2005 Dec 1;150(6):1198203.

16. Stewart BF, Siscovick D, Lind BK, Gardin JM, Gottdiener JS, Smith VE, et al. Clinical Factors Associated With Calcific Aortic Valve Disease. J Am Coll Cardiol. 1997 Mar 1;29(3):630-4.

17. Otto CM, Lind BK, Kitzman DW, Gersh BJ, Siscovick DS. Association of aortic-valve sclerosis with cardiovascular mortality and morbidity in the elderly. N Engl J Med. 1999 Jul 15;341(3):142-7.

18. Members WG, Roger VL, Go AS, Lloyd-Jones DM, Benjamin EJ, Berry JD, et al. Heart Disease and Stroke Statistics-2012 Update. Circulation. 2012 Jan 3;125(1):e2-220.

19. Aksoy Y, Yagmur C, Tekin GO, Yagmur J, Topal E, Kekilli E, et al. Aortic valve calcification: association with bone mineral density and cardiovascular risk factors. Coron Artery Dis. 2005 Sep;16(6):379-83. 